\title{
O COLÓQUIO INTERNACIONAL PERIFERIAS URBANAS, ENTRE NORMAS E INOVAÇÃO, NAS CIDADES DO SUL DA EUROPA
}

ISABEL PATO E SiLVA ${ }^{1}$

O Colóquio Internacional Periferias Urbanas, entre normas e inovação, nas cidades do sul da Europa realizou-se em Bordéus entre os dias 11 e 13 de Junho de 2008. Foi organizado por quatro centros de investigação: a Unité Mixte de Recherche (UMR) 5185, do Laboratório Aménagement, Développement, Environnement, Santé et Sociétés - ADES - da Universidade de Bordéus 3, a Unité Mixte de Recherche (UMR) 5603 da linha de investigação Société, Environnement, Territoire - SET - da Universidade de Pau e dos Pays de L'Adour e a Unité Mixte de Recherche (UMR) 5045 da linha de investigação Mutation des Territoires en Europe - TEM - da Universidade de Montpellier 3. Do lado português a participação do Centro de Estudos Geográficos da Universidade de Lisboa - CEG - nos comités científico e de organização deste colóquio resultou da colaboração desenvolvida ao longo dos últimos quatro anos com geógrafos da Unité Mixte de Recherche (UMR) 5185, do Laboratório Aménagement, Développement, Environnement, Santé et Sociétés - ADES da Universidade de Bordéus 3 e da Unité Mixte de Recherche (UMR) 5045 da linha de investigação Mutation des Territoires en Europe - TEM - da Universidade de Montpellier 3. No quadro desta colaboração formou-se uma plataforma de produção científica entre França e Portugal, dedicada aos estudos urbanos e aos processos de metropolização: o programa Perimetro ${ }^{2}$.

Neste colóquio participaram geógrafos e outros investigadores sociais. Para além da forte presença francesa, portuguesa e espanhola, o colóquio contou com a participação de investigadores italianos e gregos. A abertura ficou a cargo de Guy Di Méo, que

1 Investigadora do Centro de Estudos Geográficos. Doutoranda em Geografia Humana pela Universidade de Lisboa, bolseira da F.C.T. (isabelpato@fl.ul.pt)

2 Este programa consubstanciou-se em diversas colaborações, entre os quais se destacam como mais significativas: o colóquio “Mutations des villes méditerranéennes européennes et de leurs périphéries " (Montpellier, 2004), cujas actas foram recentemente publicadas por. Crozat D., Viala L. et Volle J.-P. (coord.), 2006, Villes méditerranéennes d'Europe et leurs périphéries; a edição de Mutations territoriales, innovations sociales, MTE/Université Paul Valéry, coll. Recherches, Montpellier; a animação, por Jorge Malheiros e Dominique Crozat, de dois ateliers no quadro das conferências da rede Metropolis (2005 em Toronto, 2006 em Lisboa) e a elaboração conjunta do n. ${ }^{\circ} 24$ da Revista Sud-Ouest Européen (2207) coordenado por Mayté Banzo, Isabel Pato e Silva e Elodie Valette. A confrontação Lisboa/Bordéus é ainda objecto da tese de doutoramento, em fase de conclusão, de Isabel Pato e Silva dedicada ao processo de construção das identidades territoriais urbanas naquelas metrópoles (consultar http://www.perimetro.cnrs.fr/). 
desafiou os geógrafos a equacionarem a periferia sob olhares mais ajustados às mudanças tecnológicas e sociais das sociedades actuais. Mayté Banzo e Frederic Tesson abriram o painel Normes, innovation, périphéries urbaines: positionnement scientiphiques no qual participaram especialistas de diferentes disciplinas: Catherine Bonvalet (demógrafa), Michel Favory (urbanista), Marie-Christine Jaillet (geógrafa), Claude Lacour (economista) e Emmanuel Negrier (politólogo). Mayté Banzo e Frederic Tesson expuseram alguns dos posicionamentos científicos de partida relativamente às questões: Porquê as periferias? Porquê inovação e norma? E, ainda, porquê Europa do Sul?

A referenciação deste evento às cidades da Europa do Sul não é uma reivindicação de um modelo de cidade. À cidade compacta, à projecção do ícone da Agora, sucede-se uma cidade construída sob o modelo do laisser faire. Serão as cidades do sul resultantes de uma fraca regulação das políticas públicas? Como interpretar os mecanismos de actuação externos à norma jurídica? Como interpretar a relação entre inovação, norma e ideologia?

Seguidamente, Marie-Christine Jaillet questiona: faz ainda sentido falar em periferia? A demógrafa lembra que a maior parte dos colóquios organizados em França sobre as periferias urbanas remontam aos anos 80. Os problemas sociais associados aos grands ensembles justificaram o interesse da geografia e de outras ciências sociais sobre a problemática das novas periferias residenciais. Na geografia social diferenciam-se duas abordagens: a primeira parte da polis e interessa-se particularmente pelas dinâmicas de transformação. Contrapõe à lógica de centro-periferia o carácter de autonomização que tende a caracterizar esta; uma segunda contrapõe à lógica de centro-periferia a lógica de rede. Enquanto na primeira perspectiva o centro é lugar de concentração, de densidade de actividades, na segunda, o centro é um nó.

Segundo Marie-Christine Jaillet, uma abordagem da periferia através da norma e da inovação abre novas possibilidades à geografia social. Nas relações entre norma e urbanismo a norma tem um carácter polissémico: do urbanismo civilizador (o ideal conforme à norma, que contribui para fazer o real), ao urbanismo regulador de usos (que produz uma ideologia territorial, o marketing, um projecto comum), à norma que se faz na comunicação. As relações entre norma e urbanismo permitem abordar as aspirações e escolhas, os arquétipos mobilizados ou, ainda, a subjectividade da recepção e interiorização da norma. Finalmente, para Jaillet, um olhar a partir da inovação e norma sobre a cidade da "periferia" permite interrogar a urbanidade fora dos limites da cidade compacta: Será a metropolização do rural um prenúncio de uma metacultura urbana?

Catherine Bonvalet salienta que a problemática da periferia na construção da ciência social do espaço foi muito importante e atravessou diferentes paradigmas. Na cidade contemporânea, à segregação social associa-se uma segregação demográfica: as famílias na periferia, os isolados no centro. Até que ponto a segregação é também o resultado de uma configuração real e virtual? Ou, por outras palavras, até que ponto o processo de segregação é também o resultado da procura de um modelo de vida que se cria na comunicação (nos media e publicidade). O periurbano, sob esta perspectiva, poderia ser interpretado como a corporalização do sucesso social (o da família e o do casal), numa sociedade em que são cada vez mais os idosos e os isolados.

O economista Claude Lacour relembra que na periferia estão, frequentemente, as actividades essenciais, o que as torna cada vez mais centrais. A periferia remete para a metrópole, para uma outra escala de entendimento da cidade. A plasticidade da escala é aqui determinante. Lacour critica os oponentes da cidade dispersa, constatando que esta crítica "tende a tornar-se norma, sem que ninguém tenha a coragem de calcular 
[os seus custos]"3. É importante pensar a organização metropolitana, tanto mais quanto se admite que o sistema urbano é frágil, cada vez mais determinado pelo valor fundiário e confrontado com novas normas e instituições.

Emmanuel Negrier faz uma análise comparada do comportamento político (traduzido nos resultados eleitorais) em áreas do periurbano de Barcelona e de Languedoc (Roussillon). Esta análise aponta para a existência de duas culturas políticas distintas (reveladas pela tendência de voto). A forte homogeneidade de comportamentos políticos, dentro das manchas administrativas verificada nas duas áreas, leva Negrier a questionar: faz sentido perspectivar uma homogeneização social e cultural do periurbano?

Para Michel Favory a dissolução do modelo centro-periferia na terceira revolução urbana vem colocar novos desafios aos académicos e actores institucionais, sobre: 1) o conhecimento e investigação em urbanismo como prática profissional e 2) o conhecimento e investigação do urbanismo no quadro da formulação das políticas públicas e da intervenção sobre a cidade. Enquanto urbanista, Favory defende a necessidade de actualizar o conhecimento sobre a cidade na sua relação com a evolução social. E pergunta: como fazê-lo sem recurso à ideologia pura?

O primeiro painel do dia 11 foi dedicado ao tema Categories, Formes et Echeles e animado por Paul Boino. Contou com a participação de Frederic Tesson, Marius Schaffer, Gianluigi Giacomel, Michel Favory e Sandrine Vaucelle. De destacar a intervenção de Frederic Tesson que se apoiou na análise de projectos e nos discursos dos actores das cidades do programa INTERREG IIIb (Programa "ATI"). Tesson mostrou de que forma este programa, vocacionado para cidades médias, veio induzir, em aglomerados nas periferias metropolitanas, a formulação de políticas de autonomização face ao centro. As conceptualizações de inovação que estão por detrás de estratégias de captação de dinâmicas de crescimento urbano permitem colocar a questão: a que nível se situa a norma que os actores consideram inovadora?

No período da tarde o painel Enjeux de la publicisation foi introduzido por Mayté Banzo e animado por Martin Vanier. Num dos painéis mais diversificados, tanto nos temas como nas abordagens das comunicações, merecem destaque a intervenção de Vincent Banos e Bruno Sabatier e a de Sandrine Vaucelle. Na primeira, intitulada Les espaces périurbains non bâtis entre publicisation et privatisation: de nouvelles sociabilités hybridant rural et urbain, os autores debruçam-se sobre os processos jurídicos, sociais e políticos ligados à privatização e à publicização, defendendo que a investigação urbana tem privilegiado o estudo dos processos de privatização face à publicização, entendida como a produção da coisa pública. A propósito deste estudo Mayté Banzo identifica dois sentidos atribuídos ao processo de publicização: o das práticas sociais em espaço público e o do voluntarismo político, norteado pelo objectivo do être ensemble.

Neste mesmo painel Sandrine Vaucelle apresentou parte de um projecto de investigação que pretende estudar os custos de manutenção e distribuição de água, em áreas urbanas com diferentes formas construtivas e processuais, nas periferias da aglomera-

3 Com interesse na investigação nesta matéria sugere-se a consulta do blog http://ocupacaodispersa.blogspot.com/2008/03/seminrio-aproximaes.html onde, na sequência do seminário Custos e Benefícios, à Escala Local, de uma Ocupação Dispersa, se apresenta um projecto de investigação que abre a possibilidade de diálogo a todos os interessados sobre o tema em geral ou sobre as áreas temáticas que compõem o projecto (designadamente ocupação do território, externalidades ambientais, infra-estruturas, mobilidade, mercado imobiliário, qualidade de vida, modelos de custo/ benefício). 
ção bordelesa ${ }^{4}$. Este estudo permite colocar em evidência as múltiplas redes e uma dinâmica inter escalar complexa na área estudada, em parte resultado do processo decisional de planeamento e gestão urbana, mas, também, resultado de uma "autoprodução" (ou auto-organização) que se dá em paralelo, norteada pela complexidade intrínseca ao processo de urbanização.

No quadro do Programa Perimetro, Teresa Barata Salgueiro animou o painel da manhã do segundo dia do Colóquio dedicado ao tema: Pour une nouvelle problématisation de la ségrégation socio-spatial. Destacam-se as comunicações de Dominique Crozat e de Isabel Pato e Marluci Menezes. No quadro do mesmo programa Jorge Malheiros, Ana Paula Horta e Maria Manuela Mendes intervieram no painel animado por Jean-Pierre Augustin Sur les marges: pratiques spatiaux et stratégies identitaires no período da tarde.

A adopção de uma noção de "inovação ordinária" no sentido dado por Alter, levou Isabel Pato e Marluci Menezes a procurarem uma metodologia para aferir as dinâmicas sociais associadas à recomposição social numa freguesia do periurbano de Lisboa. Numa comunicação intitulada Inovação e norma na gestão do periurbano colocaram-se em evidência as múltiplas redes e as complexas dinâmicas inter escalares que interferem na gestão social urbana. Questionaram a forma como estes actores vêem e agem a propósito e sobre a precariedade, o que os levou a perguntar: será que as lógicas normativas de regulação do urbano são proeminentes na promoção da "inclusão social"? Se não, em que medida a capacidade inventiva destes contextos engendra mecanismos de inclusão? A partir dos discursos produzidos pelos actores sociais locais sobre a diversidade e precariedade, detectou-se que as acções auto-produzidas localmente, particularmente nos domínios da habitação social, acção social e cultura, tendiam para a normalização do edificado, da gestão urbana e da intervenção social para a inserção. Os processos generativos do periurbano de Lisboa, dos anos 70 e 80, nas suas componentes urbanística, social e cultural tendem a perder especificidade e expressão nas políticas e práticas sócio-urbanísticas contemporâneas.

Para Dominique Crozat é o jogo com a norma que permite às populações de baixo rendimentos aceder à propriedade em espaços sobrevalorizados, em virtude da pressão turística e migratória. Crozat destaca a complexidade da noção de justiça espacial e social que, essencialmente devido aos processos desenrolados na sombra, geram efeitos perversos da norma legal que pretende assegurar aquela justiça. As habitações não licenciadas do periurbano de Languedoc-Rousillon parecem satisfazer interesses variados, incluindo o das municipalidades que as denunciam. $\mathrm{O}$ jogo com a norma permite aligeirar os confrontos entre estas formas de habitar e a multiplicidade de regulamentações nacionais e europeias, para estas áreas classificadas como zonas inundáveis ou áreas protegidas.

4 Nas definições do INSEE a unidade aglomeração reporta-se a um critério de continuidade construtiva. "La notion d'unité urbaine repose sur la continuité de l'habitat: est considérée comme telle un ensemble d'une ou plusieurs communes présentant une continuité du tissu bâti (pas de coupure de plus de 200 mètres entre deux constructions) et comptant au moins 2000 habitants [...]" (http://www.insee.fr/fr/methodes/default.asp?page=definitions/unite-urbaine.htm). Por seu lado, a comunidade urbana, órgão politicamente eleito com poderes deliberativos e executivos, agrupa diversas communes que se associam para a condução conjunta de projectos de desenvolvimento urbano do seu território. A CUB - Commaunité Urbaine de Bordeaux - é uma entidade política de gestão do espaço. Criada nos anos 60 , integra actualmente 27 communes. A sua constituição absorveu parte das competências dos municípios, designadamente em matéria de infra estruturas e transportes 
Jorge Malheiros abriu o painel Sur les marges: pratiques spatiaux et stratégies identitaires com um enquadramento da intervenção pública em bairros da periferia de Lisboa marcados por processos de racialização de grupos, processos de estigmatização territorial e de conflitos geracionais. No quadro desta intervenção distinguiu os processos de reconfiguração identitária desenvolvidos em bairros marcados por uma cultura negra ou crioula, sublinhando a combinação de elementos portugueses, africanos e afro-americanos nos processos de reconfiguração identitária destes bairros. Sendo esta marcada pelo conflito, Malheiros defende a análise dos focos de tensões e propõe formas de negociação das mesmas.

Ana Paula Horta partiu também do discurso estigmatizador dos bairros degradados multiculturais na periferia de Lisboa e das suas implicações na produção de novas formas de organização sócio-espacial reveladoras de novas fronteiras de exclusão urbana e de isolamento político e simbólico. Examinou a complexa relação entre espaço e identidade, mais especificamente o impacto das políticas urbanas nos processos de formação identitária colectiva. Tendo como pano de fundo o bairro periférico multicultural do Alto da Cova da Moura, a autora questiona: como é que o discurso dominante sobre o bairro veiculou novas formas de categorização e hierarquização social? São os processos de construção de uma identidade colectiva espacial, num quadro de relações inter-étnicas e de pertença local, uma prática de contestação do discurso dominante? Que noção de cidadania multicultural local está em jogo? Que tipos de inovação política e de legitimação de valores devem estar na base do direito associado à cidade e ao território?

Maria Manuela Mendes discutiu a relação entre a periferização e os padrões residenciais dos imigrantes na Área Metropolitana de Lisboa, considerando os fluxos migratórios mais recentes. O padrão residencial resultante da fixação dos imigrantes destes novos fluxos segue o anteriormente observado por diversos autores para grupos imigrados nos anos 70 e 80: metropolização em torno de Lisboa e de Setúbal e crescente centralidade de Faro. Também alguns grupos étnicos com cidadania nacional, como é o caso dos ciganos, tendem a dispersar-se de forma privilegiada pelos concelhos que gravitam à volta de Lisboa (Barreiro, Amadora, Cascais, Sintra e Loures).

Yve Raibond equacionou a ideologia territorial a partir da investigação dos skaterparks numa comunicação intitulada Les skates-parks: des lieux qui fabriquent l'identité masculine. Apesar de um padrão de apropriação fortemente masculinizado, a análise dos discursos dos responsáveis pela política urbana revela que as políticas públicas tendem a negar a categoria género e a encarar estes espaços como lugares de canalização da violência dos jovens. Por outro lado, esta cultura urbana da periferia tende a abranger públicos de territórios cada vez mais vastos, designadamente através de eventos como o festival de Culturas Urbanas, apoiados pela política de cidade.

Na manhã do terceiro dia do Colóquio de destacar no painel Des Potencialités pour de nouveaux modes de vie a comunicação de Mélina Germes. A geógrafa interroga-se sobre a natureza da intervenção artistico-urbanística enquanto acção para a produção do lugar urbano. Adoptando uma perspectiva constitutivista da análise do discurso, apoia-se nos discursos recolhidos durante uma intervenção pública de artes plásticas, desenvolvida pela associação Bruit du Frigó no bairro do Plan d'Aou, em Marselha. O estudo apresentado por Mélina Germes é interessante, fundamentalmente, no que revela sobre os processos de qualificação do urbano por via das práticas, designadamente práticas de participação e implicação dos habitantes em iniciativas de qualificação do habitat. Os propósitos da intervenção revelados nos discursos dos artistas presentes permitem questionar a atribuição de um estatuto periférico a estes espaços. 
O encerramento do colóquio foi marcado no período da manhã pela sessão dedicada ao tema As Periferias da Península Ibérica, animado por Ângela De Meer, com as excelentes intervenções dos geógrafos Teresa Barata Salgueiro (CEG - Universidade de Lisboa) e Lourenzo López Trigal (Universidade de Léon). Para Teresa Barata Salgueiro a inovação não é uma questão de distância, de extensão ou descontinuidade. Não há uma só lógica, mas a combinação de diferentes lógicas. A multiplicidade de factores que interferem no processo de inovação põe em causa o modelo centro-periferia, não se tratando de uma questão de distância. Quando falamos de bairros sociais, por exemplo, múltiplos factores concorrem para uma desqualificação territorial. Neste sentido, a "qualificação" pode constituir uma abordagem mais pertinente que a da distância. Encontramos inovação no alojamento, tanto dos bairros ditos "clandestinos" como dos condomínios fechados. Nos primeiros, a inovação estaria na autoconstrução, no custo do terreno, na criação de áreas de moradias extensas, enquanto nos segundos ela residiria na casa, na segurança e na plasticidade dos serviços. Finalmente, a inovação no consumo, encontrar-se-ia nas grandes superfícies, no centro comercial regional. $\mathrm{O}$ gigantismo do comércio leva o centro à periferia. Todas estas inovações participam na configuração de uma metrópole fragmentada. Esta constitui um território ligado pelas práticas geradoras de mobilidade, também ela fortemente segregativa e excludente. A metrópole fragmentada obriga-nos a olhar para o sentido sócio-político da inovação, integrando democracia, organização espacial, planeamento e gestão e, também, novas tecnologias.

Numa perspectiva diferente L. Lopez Trigal mostrou as formas e as tentativas de conciliação entre processos de transformação urbana e projectos de competitividade das cidades. A noção de cidade inovadora mistura-se com vocábulos que são imprecisos: a cidade do conhecimento, a cidade criativa... De que modo a nova economia impulsiona a massa crítica universitária ou potencia a produção de cultura? São os perigos da redução do mega-evento ao marketing urbano, quando os grandes projectos são excessivamente exógenos. Sob esta matriz L. López Trigal procedeu a uma revisão crítica dos planos de grandes projectos em diferentes cidades de Espanha (a Exposição Universal de Sevilha; Madrid - capital do Sudoeste da Europa; Bilbau e o seu Museu Guggenhein; Valência - complexo logístico de Espanha, e a Exposição Internacional de Saragoça, entre outros). A ausência de partenariados nalguns projectos, o desfasamento entre a cidade sonhada (que expõe a cidade ao fachadismo) e os impactos no emprego, nos recursos, no saber, são alguns das questões que se colocam à afirmação destes projectos urbanos como intervenções efectivamente inovadoras.

Finalmente, no período da tarde Martin Vanier dinamizou o debate que encerrou o colóquio, sendo este um dos melhores momentos do encontro pela sua originalidade e resultados. Vanier abriu com uma síntese de algumas marcas do colóquio, destacando que $90 \%$ das intervenções se interessaram pela inovação e questionando: não será a periferia a melhor forma que temos de falar do que nos desconcerta ou do que ainda não conseguimos apreender?

No debate os operadores da cidade e da Comunidade Urbana de Bordéus foram colocados frente aos investigadores ${ }^{5}$, encenando um jogo de papéis. Três questões fundamentais resultaram deste confronto:

5 Participaram neste debate B. Bertoncello, P. Boino, G. Cortes, F. Cuillier, A. De Meer, F. Dureau e J.P. Volle. Françoise Dureau animou também o atelier "Recomposition des formes" na manhã do dia 12 de Junho. 
a) Se as formas inovadoras estão para além do universo normativo do espaço, no sentido da norma jurídica, é necessário produzir saber para além do discurso normativo. Foi Jean-Paul Volle que, do lado dos académicos, respondeu a este desafio (curiosamente) fazendo uso da sua experiência enquanto planeador: para capturar as formas inovadoras de produção de espaço, que extravasem o domínio normativo, é necessária uma antecipação do processo de pesquisa.

b) Existe algum desconhecimento mútuo dos interesses centrais de cada uma das partes presentes no debate. Por um lado, a produção académica parece não responder aos problemas colocados na prática urbanística. Por outro, as inovações metodológicas para a observação de espaços residenciais complexos mostram que a tendência para a produção de uma norma sob uma lógica de perímetro (sem atender ao que se passa dentro desses perímetros e sem colocar esses perímetros em relação) merece ser questionada. As tensões entre o paradigma de intervenção urbana voltada para o projecto, normalmente privado e rápido, e o paradigma do ordenamento, lento e participativo, são sobretudo sentidas do lado dos académicos. Não se trata apenas de dimensões espacio-temporais distintas, mas de duas lógicas de entendimento da transformação urbana.

c) Porque o campo político tem leis que lhe são próprias e que não se estendem nem são apreensíveis ao nível da gestão territorial será necessário explorar as injunções entre o saber do território e o saber político (Boino).

As conclusões deste colóquio, elaboradas por Dominique Crozat e Elodie Valette, sublinharam as novas possibilidades epistemológicas das abordagens que questionem os conceitos de base e a redefinição de vocabulários, as marcas e as ausências, e, finalmente, a reflexividade e o posicionamento dos investigadores. Não somos tão neutros quando desejamos ou pensamos ser. A este propósito, Crozat recordou uma questão de JeanPierre Augustin no debate: ao interessarmo-nos mais pelos pobres do que pelos ricos não estaremos a contribuir para a fabricação dos pobres? É necessário pensar nos efeitos da nossa acção.

Grande parte da periferia é o resultado de um ideário de produção de uma categoria normativa. Inscreve-se numa cultura urbana que a revela e a promove. Entretanto, sobre o mesmo edificado a cidade evolui. Quando os bairros sociais foram construídos, os seus projectos, assim como as suas políticas, foram considerados inovadoras, "piloto"... Hoje essa norma é questionada e outras questões se colocam: Qual é a legitimidade da intervenção pública sobre a (re)composição social nos diferentes espaços metropolitanos? O que significa regular a (re)composição social do ponto de vista dos direitos individuais? À luz destas novas questões, os mecanismos sociais e culturais de produção de urbanidade ultrapassam largamente o modelo centro-periferia. Precisamos de actualizar a temporalidade e, simultaneamente, privilegiar estudos sobre as relações periferia-periferia.

É interessante verificar que, na maioria das intervenções, a periferia surge como espaço de refúgio, de tranquilidade face ao conflito e debate social. É grande a diversidade de espaços metropolitanos e urbanos estudados: o periurbano (nas suas diversas configurações), os bairros urbanos mais desqualificados, os grandes espaços comerciais, os parques temáticos... a riqueza do material empírico trazida a este colóquio. Apesar da sobrevalorização das representações centro-periferia e cidade-campo, em grande número de comunicações, a partilha de pressupostos, de propostas metodológicas e de evidências empíricas capazes de dar novos sentidos epistemológicos ao estudo da cidade, são o que de melhor se retira deste colóquio. 
A diversidade de espaços metropolitanos esteve também presente na excursão pela periferia de Bordéus realizada no dia 13 de Junho. Visitou-se o Parc du Bourgailh (Pessac), o Garage Moderne (Quartier de Bacalan, Ville de Bordeaux), o Hameau de Bages (Pauillac) e a Winery ("Un temple de la dégustation au coeur du Médoc", Arsac). A gastronomia do sudoeste foi servida ao almoço na quinta-albergue do château "GuittotFellonneau" (Macau). Entre esta quinta e a Hameau de Bages seguiu-se parte da Route des Châteaux du Médoc. 